\title{
Oligo swapping method for in vitro DNA repair substrate containing a single DNA lesion at a specific site
}

\author{
Mika Yukutake, Mika Hayashida, Narumi Shioi Aoki and Isao Kuraoka ${ }^{*}$ (D)
}

\begin{abstract}
Background: A wide variety of DNA lesions interfere with replication and transcription, leading to mutations and cell death. DNA repair mechanisms act upon these DNA lesions present in the genomic DNA. To investigate a DNA repair mechanism elaborately, an in vitro DNA repair substrate containing DNA lesions at a specific site is required. Previously, to prepare the substrate, phagemid ssDNA and DNA lesion-harboring oligonucleotides were employed with considerable amounts of DNA polymerase and DNA ligase. However, preparing in vitro DNA repair substrate in general is difficult and labor intensive.

Results: Here, we modified the construction method of in vitro mismatch repair substrate using a nicking-endonuclease, which produces gap corresponding to the ssDNA in the plasmid DNA, and swaps DNA lesion-containing oligonucleotide upon addition of restriction enzyme and T5 exonuclease. This modified method is able to produce in vitro DNA repair substrates containing adenine:cytosine mismatch basepair, 8-oxoG, and uracil. The DNA repair enzyme, each Fpg, hOGG1 could cleave an 8-oxoG-containing DNA substrate, the mixture of UDG and APE1 could cleave a uracil-containing DNA substrate. Omitting a column purification step, DNA repair substrates were prepared by one-pot synthesis.
\end{abstract}

Conclusions: We were able to prepare in vitro DNA repair substrates using this simple method involving restriction enzymes and T5 exonuclease. It is anticipated that this method, termed as "Oligo Swapping Method", will be valuable for understanding the DNA repair machinery.

Keywords: DNA lesion, In vitro DNA repair substrate, In vitro assay

\section{Background}

Although genomic DNA supposedly contains error-free genetic information to facilitate the proper cell functioning, yet it is prone to damage, deterioration, and modifications due to environmental and endogenous factors. The induced DNA lesions interfere with DNA and RNA synthesis during replication and transcription, respectively, leading to mutations and cell death [1]. As a result, these genomic mutations and subsequently, the disruption of cellular processes may cause cancer, congenital diseases, and aging. To maintain genomic integrity, cells possess several DNA repair pathways such as nucleotide excision repair (NER), which operates primarily on genotoxic chemicals or UV irradiation-induced bulky helix-distortion (e.g. CPD, 6-

\footnotetext{
* Correspondence: kuraoka@fukuoka-u.ac.jp

Department of Chemistry, Faculty of Science, Fukuoka University, 8-19-1 Nanakuma, Jonan-ku, Fukuoka 814-0180, Japan
}

4 pp),; base excision repair (BER) (short- and long-patch repairs), which is used for non-bulky and non-helix-distorting DNA modifications induced by alkylation, oxidation (e.g. 8-oxoG), and deamination (e.g. uracil); and mismatch repair (MMR), which mends the mismatch base pairings during DNA replication. DNA repair systems are highly conserved from bacteria to humans $[2,3]$.

To analyze DNA repair mechanisms in vitro, we required DNA repair substrates containing a DNA lesion at specific site. For the in vitro BER assay for short patch repair, chemically synthesized DNA lesion bearing oligonucleotides annealed with complementary strands were employed as DNA lesion substrates [4, 5]. Because DNA glycosylases of BER enzymes can digest a short oligonucleotide substrate (10-30-mer) containing a DNA lesion, it is not difficult to prepare DNA substrates for incision reaction during BER. On the other hand, in case of in vitro NER assay $[6,7]$, at least $\sim 120$-bp long DNA

(c) The Author(s). 2018 Open Access This article is distributed under the terms of the Creative Commons Attribution 4.0 International License (http://creativecommons.org/licenses/by/4.0/), which permits unrestricted use, distribution, and 
substrates for the reaction are required [8]. In addition, in vitro long patch BER [9] is also required to allow the repair action of DNA polymerase and proliferating cell nuclear antigen (PCNA) on the plasmid to fill in the gap [10]. Thus, the DNA substrates containing lesions were produced by in vitro DNA synthesis using single strand plasmid DNA annealed chemically with synthesized lesions-bearing oligonucleotide and DNA polymerase and ligase. Moreover, to observe DNA repair during NER and BER, covalently closed circular DNA substrate is required because the repair systems do not act upon linear DNA substrate. Additionally, for MMR assay, the DNA mismatch substrates were produced by a hybridization reaction between a circularized ssDNA and a digested plasmid DNA [11]. Although these methods are useful, they carry limitations like difficulty in preparation and high expenditure.

In vitro DNA MMR substrate construction method is a reasonable one to induce the DNA lesion at the specific site. In this method, a nicking endonuclease produces a ssDNA stretch on a purified dsDNA plasmid for replacement by synthetic oligonucleotide and thereafter, DNA ligase seals the nick site. This was reported by Wang et al. reported in 2000 and 2002 [12, 13]. Later, Du et al. reported the procedure in 2011 [14] with modifications, i.e. adding a purification step of ssDNA by using the streptavidin linked oligonucleotides. Although these methods are used for MMR assays, they can also be used potentially to induce DNA lesions in plasmid DNA.

Here, we have modified the method by addition of a restriction enzyme and $\mathrm{T} 5$ exonuclease that is capable of removing linear dsDNA and nicked plasmid DNA. By the Oligo Swapping Method, we produced in vitro DNA repair substrates containing adenine:cytosine (A:C) mismatch, 8-oxoG, and uracil residues at specific sites. This method allows execution of one-pot reaction without any DNA purification steps during the substrate production.

\section{Methods}

\section{Enzymes and chemicals}

Nt.BbvCI nicking endonuclease, EcoNI, Fpg, hOGG1, UDG, APE1, and T5 exonuclease were purchased from New England Biolabs (Ipswich, MA, USA). KpnI, SacI, and T4 DNA ligase were from TaKaRa (Otsu, Shiga, Japan). Enzyme reactions $(10 \mu \mathrm{L})$ for DNA repair assay were carried out according to the manufacturer's instructions and were terminated by adding $2 \mu \mathrm{L}$ Gel Loading Dye, Purpule from New England Biolabs.

\section{Oligonucleotides}

For construction of pBS2-SDL, 5'-CCCGGTACCCCCGAATTCGCCTCAGCCCTAATCGAGGCGTTTCCCTCAGCGGCTGCAGCACGAGCTCCCC-3' and 5' -GGG
GAGCTCGTGCTGCAGCCGCTGAGGGAAACGCCT CGATTAGGGCTGAGGCGAATTCGGGGGTACCGG G-3' were synthesized and purified with cartridge at FASMAC (Kanagawa, Japan). Both oligonucleotides were hybridized and digested with KpnI and SacI to produce synthetic 64-bp DNA duplex. The products were purified by PCR Clean-up kit (MACHEREY-NAGEL, Düren, Germany). For synthesis of the DNA substrate plasmid which contains single DNA lesions, mismatch oligos (5'-p-TCAGCCCTAATCGAAGCGTTTCCC-3'; $\underline{\mathrm{A}}$ is mismatch base; $p$ is phosphate), 8 -oxoG oligos ( $5^{\prime}-\mathrm{p}$-TC AGCCCTAATCGA8GCGTTTCCC-3'; 8 is 8-oxoG; p is phosphate), and uracil oligos (5'-p-TCAGCCCTAATCGAUGCGTTTCCC-3'; $\mathrm{U}$ is uracil; $\mathrm{p}$ is phosphate) were synthesized and purified by HPLC at FASMAC.

\section{Construction of $\mathrm{pBS2}-\mathrm{SDL}$}

The pBlueScript II KS (-) Single DNA Lesion (pBS2-SDL) plasmid was constructed by replacing the $K p n I-S a c I$ fragment of pBlueScript II KS (-) with the synthetic 64-bp DNA duplex containing the target site for nickase Nt.BbvCI, and the restriction enzyme EcoNI (Fig. 1b). Plasmid DNAs were purified by NucleoSpin Plasmid. The construct pBS2-SDL was checked by DNA sequencing.

\section{Standard procedure for synthesis of in vitro DNA repair substrate}

Nicking reaction mixture $(20 \mu \mathrm{l})$ was comprised of pBS2-SDL ( 3 pmol) and Nt.BbvCI (5 units) in reaction buffer containing $50 \mathrm{mM}$ Potassium acetate, $20 \mathrm{mM}$ Tris-acetate $(\mathrm{pH}$ 7.9), $10 \mathrm{mM}$ Magnesium acetate, and $100 \mu \mathrm{g} / \mathrm{ml}$ bovine serum albumin. The reactions were incubated at $37{ }^{\circ} \mathrm{C}$ for $3 \mathrm{~h}$ and then at $80{ }^{\circ} \mathrm{C}$ for $20 \mathrm{~min}$. They were then purified using PCR Clean-up kit (MACHEREY-NAGEL GmbH \& Co.) to remove the 24-mer oligonucleotides digested by Nt.BbvCI. After purification, the DNA sample mixture (about $25 \mu \mathrm{l}$ ) prepared in the same reaction buffer was incubated with chemically synthetized 24-mer DNA lesion oligonucleotide $(15 \mathrm{pmol})$ at $95{ }^{\circ} \mathrm{C}$ for $5 \mathrm{~min}$, $70{ }^{\circ} \mathrm{C}$ for $5 \mathrm{~min}$ and $\mathrm{RT}$ for $15 \mathrm{~min}$ for an annealing reaction. For DNA ligation reactions, the mixtures were incubated overnight at $16{ }^{\circ} \mathrm{C}$ in the presence of ATP (final concentration $1 \mathrm{mM}$ ) and T4 DNA ligase (800 units) in $30 \mu \mathrm{l}$ system, and the reaction was terminated by incubating at $65{ }^{\circ} \mathrm{C}$ for $10 \mathrm{~min}$. For restriction endonuclease $E c o \mathrm{NI}$ reaction, $E c o N I$ ( 5 units) was added to the reaction sample $(30 \mu \mathrm{l})$ followed by incubation of the mixtures at $37^{\circ} \mathrm{C}$ for $1 \mathrm{~h}$ and at $65{ }^{\circ} \mathrm{C}$ for $20 \mathrm{~min}$. For T5 exonuclease reaction, the mixtures were incubated with $\mathrm{T} 5$ exonuclease (5 units) at $37^{\circ} \mathrm{C}$ for $1 \mathrm{~h}$. For DNA purification step, T5 exonuclease treated mixtures were purified by PCR Clean-up kit (MACHEREY-NAGEL). For one-pot synthesis, first DNA purification step was omitted. 


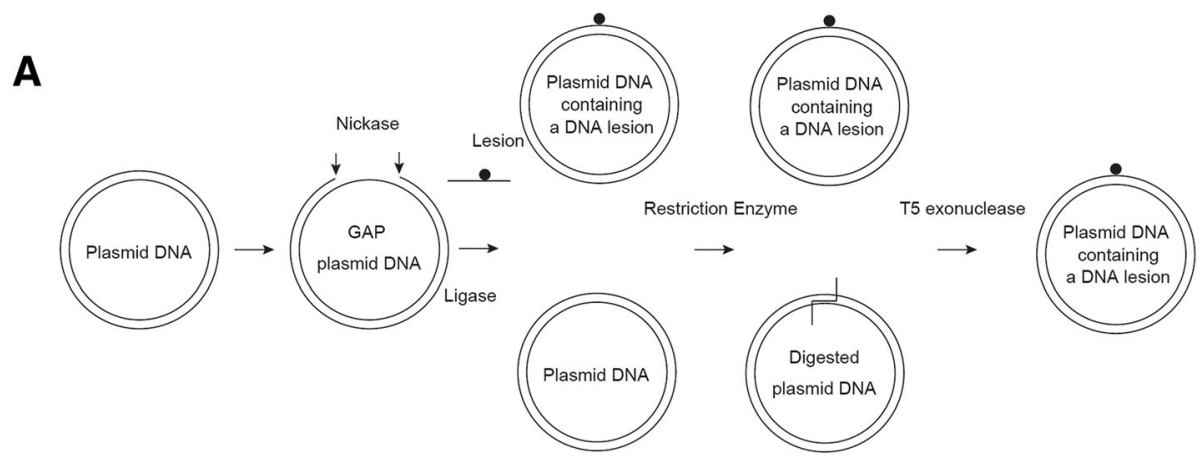

B
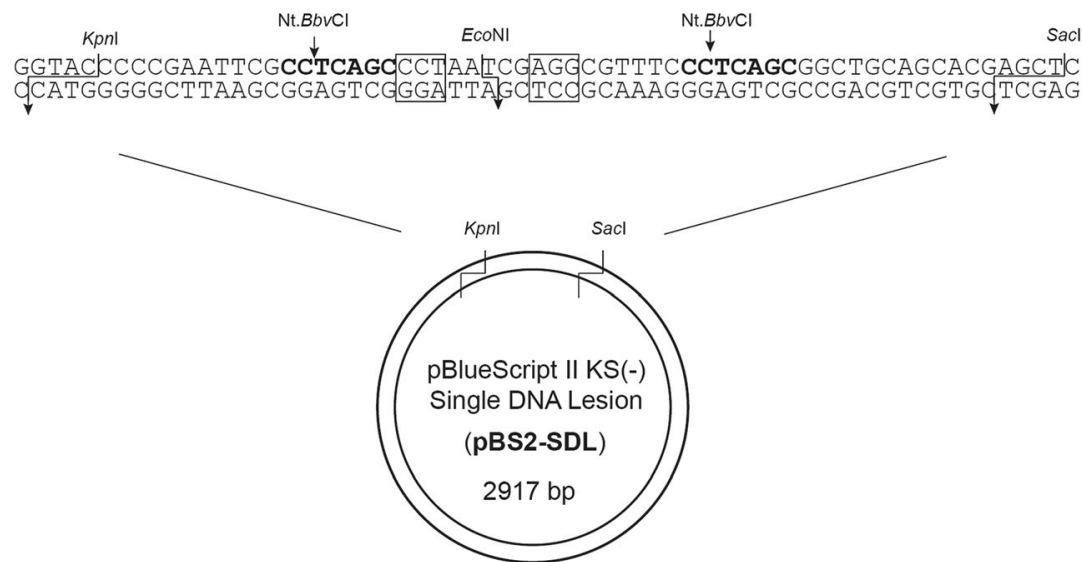

Fig. 1 a Experimental design. The plasmid pBS2-SDL was digested with a nicking endonuclease. An oligonucleotide containing a DNA lesion was hybridized with gap plasmid and ligated using T4 DNA ligase. Original plasmids in the sample are digested with restriction enzymes, except for DNA lesion bearing plasmids. T5 exonuclease cuts only the linear DNA plasmids digested by EcoNI, and does not work on sealed DNA plasmids containing a DNA lesion. $\mathbf{b}$ Covalently closed circular duplex DNA containing a single lesion. Sixty four-basepair oligonucleotides containing a single DNA lesion site within the ECoNI restriction enzyme site, two nicking endonuclease sites and the plasmid pBS2-SDL (2917 bp) are shown diagrammatically

\section{Agarose gel electrophoresis}

The sample DNA substrates were subjected to $0.8 \%$ agarose gel, and visualized by ethidium bromide staining. DNA fragments in the agarose gel were analyzed using Image J software. \% contamination $=($ Open circular DNA + liner DNA / (Open circular DNA + liner DNA + covalently closed circular DNA) $\times 100$.

\section{Results \& discussion}

An experimental design has been shown in Fig. 1a. The plasmid DNA, pBluescript II KS(-) Single DNA lesion (pBS2-SDL), containing two nicking sites for endonuclease Nt.BbvCI and restriction endonuclease EcoNI, (Fig. 1b) was digested by Nt.BbvCI to produce 24-mer gap region of ssDNA on the plasmid. The digested oligonucleotides were then removed from the plasmid by a DNA purification step, followed by addition of the oligonucleotide containing DNA lesion. After ligation, the plasmid DNA was digested by EcoNI to remove plasmid containing residual non-lesion oligonucleotides. The reaction mixtures were digested by $\mathrm{T} 5$ exonuclease that is capable of removing linear dsDNA and nicked plasmid DNA, but not supercoiled plasmid DNA $[15,16]$. This method allows production of site-specific lesion-bearing DNA substrates.

We tested the efficacy of this method in producing A:C mismatch substrates (Fig. 2a) using mismatch oligonucleotide. Figure 2b shows experimental procedure for purification of pBS2/A:C. Purified pBS2-SDL (Fig. 2c, line 2) was digested by $\mathrm{Nt} . \mathrm{Bb} v \mathrm{CI}$ to produce the 24-mer gap and was purified to remove Nt.BbvCI-digested oligonucleotides (Fig. 2c, line 3). The mixture was incubated with T4 DNA ligase at $16{ }^{\circ} \mathrm{C}$ overnight (Fig. 2c, line 4), followed by EcoNI digestion (Fig. 2c, line 5). The mixture was finally treated with T5 exonuclease and purified by DNA purification step (Fig. 2c, line 6). Post purification, $\mathrm{pBS} 2 / \mathrm{A}: \mathrm{C}$ DNA substrate was observed as one single band on $0.8 \%$ agarose gel.

To confirm the presence of A:C mismatch in this DNA substrate, each of the purified plasmid DNA strands was 
A

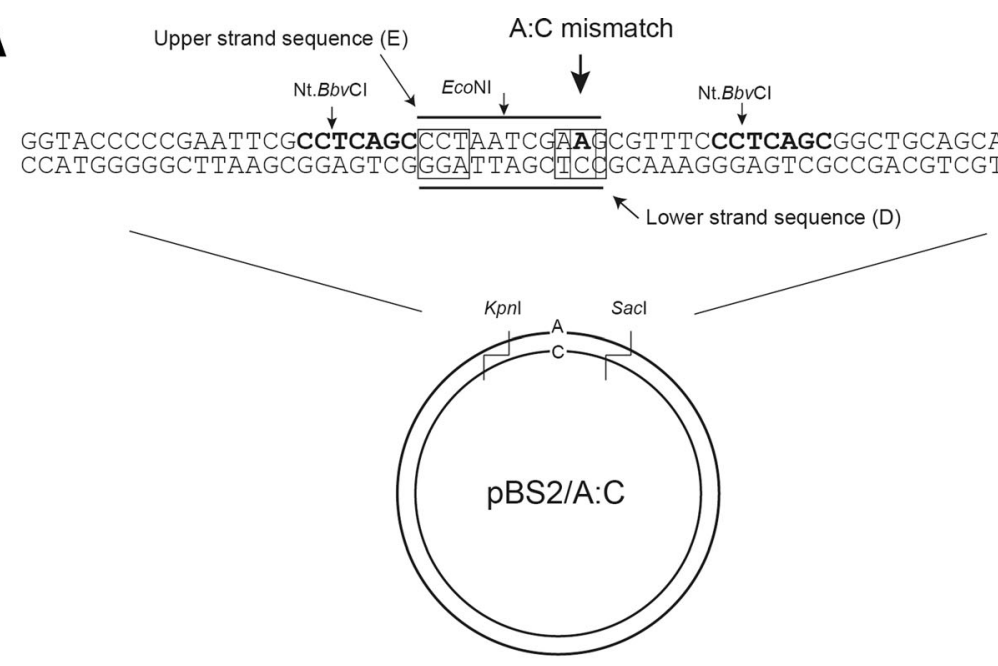

B

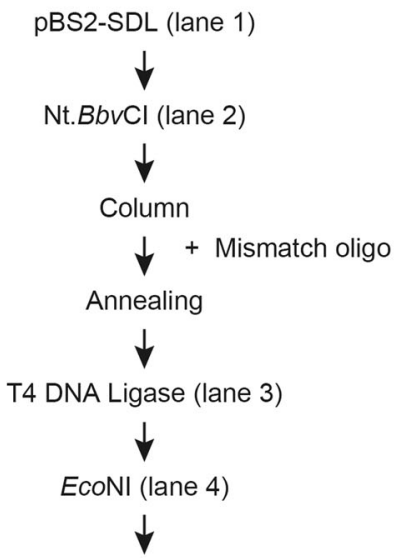

T5 exonuclease (lane 5)

D

Lower strand sequence

C $T$ T $C G \quad A T$ T A G $G$

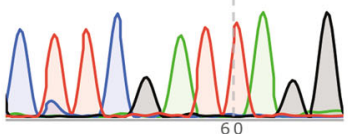

$\uparrow$

$\mathrm{A}: \mathrm{C}$ mismatch site
C
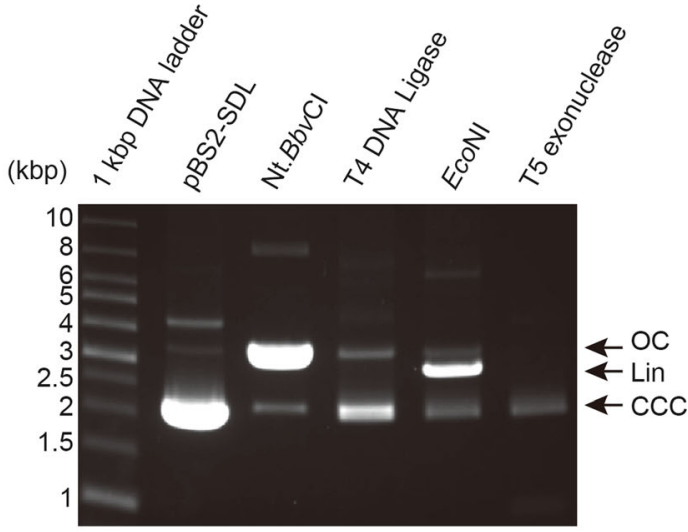

$\begin{array}{lllll}1 & 2 & 3 & 4 & 5\end{array}$

E

Upper strand sequence

C C T A A T C G A G G

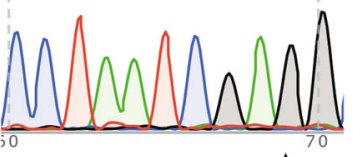

$\uparrow$

$A: C$ mismatch site

Fig. 2 Preparation of DNA template (A:C mismatch substrate) with $A: C$ mismatch at a defined position. a Upper strand sequence containing $A$ base and lower strand substrate containing original $\mathrm{C}$ base in $\mathrm{pBS2} / \mathrm{A}: \mathrm{C}$ are shown diagrammatically. $\mathbf{b}$ Experimental procedure for purification of pBS2/A:C. c Aliquots from various steps of the purification were analyzed on $0.8 \%$ agarose gel, and the DNA substrates were visualized by staining with EtBr. Lane 1, pBS2-SDL; lane 2, Nt.BbvCl-treatment; lane 3, T4 DNA ligase-treatment; lane 4, EcoNI-treatment; lane 5, T5 exonucleasetreatment. Lower panel shows final purified DNA products (\%). Open circular DNA (OC), linear DNA (Lin), and covalently closed circular DNA (CCC) are indicated by arrow. $\mathbf{d}$ Upper strand sequence containing $A$ base in $\mathrm{pBS} 2 / \mathrm{A}: \mathrm{C}$ was sequenced. An A:C mismatch site is indicated by the arrow. e Lower strand sequence containing base $A$ in pBS2/A:C was sequenced. The A:C mismatch site is indicated by the arrow 


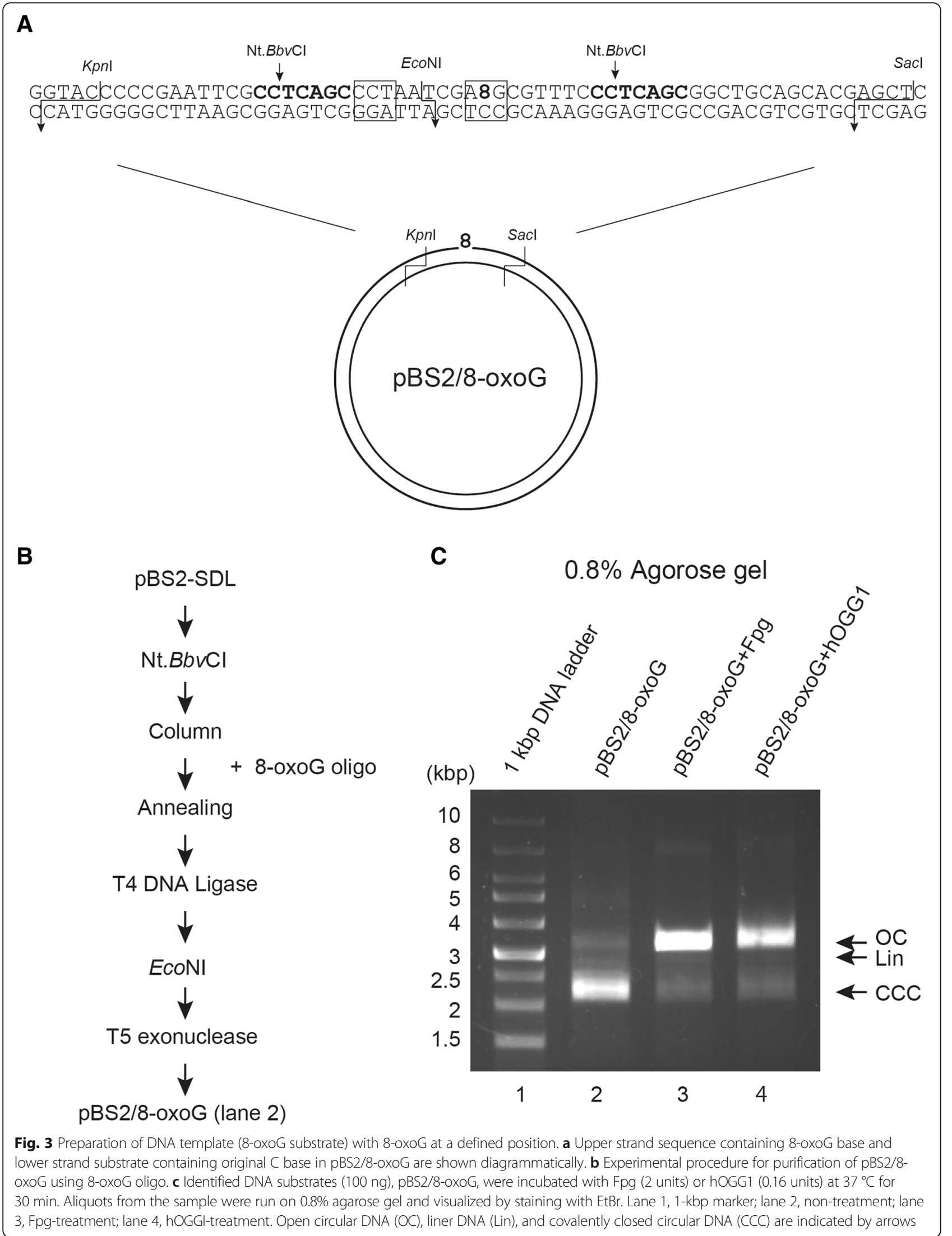




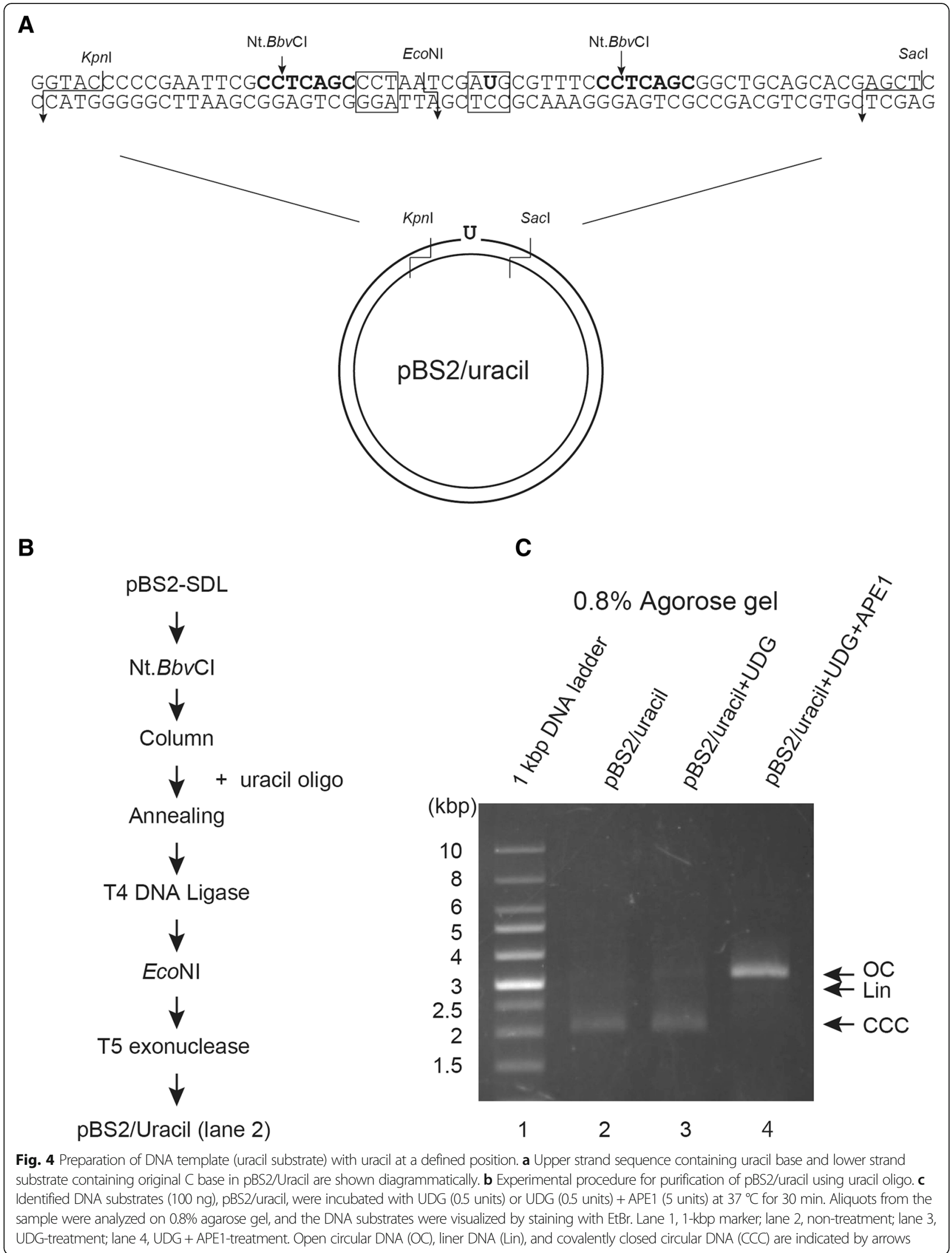


sequenced. While the upper strand sequence showed mainly $\mathrm{T}$ and a little $\mathrm{C}$ at the mismatch position, the lower strand sequence showed only $\mathrm{G}$, indicating that this method can produce A:C mismatch on the DNA substrate. We observed slight contamination with the original plasmid.

Next, we tried to introduce an oxidative DNA lesion 8-oxoG in the plasmid DNA using this method. 8-oxoG was located within/at the EcoNI recognition site of the oligonucleotide, causing inhibition of EcoNI mediated digestion (Fig. 3a). Figure 3b shows the experimental steps followed for the purification of pBS2/8-oxoG. To confirm if this in vitro DNA repair substrate contained 8-oxoG, the substrates purified by this method were treated with Fpg [17, 18] or hOGG1 [19]. The two DNA repair enzymes act as both an $\mathrm{N}$-glycosylase and an AP-lyase. The N-glycosylase activity releases damaged purines from double stranded DNA, generating an AP site. The AP-lyase activity cleaves both at $3^{\prime}$ and 5' ends of the AP site, thereby removing it and leaving a single-base gap. When pBS2/8-oxoG DNA substrates were incubated with these enzymes, open circular conformation of plasmid DNA substrate was observed on $0.8 \%$ agarose gel, whereas linear DNA was not seen (Fig. 3c, lanes 3 and 4). In addition, most of the supercoiled DNA substrates converted to open circular form, indicating the presence of 8-oxoG lesion in this DNA substrate.
For further applications of this method, we introduced a deaminated uracil as the DNA lesion on the plasmid DNA. Uracil was positioned at the EcoNI recognition site of the oligonucleotide to inhibit EcoNI digestion (Fig. 4a). Figure 4b shows the experimental procedure for purification of $\mathrm{pBS} 2 / \mathrm{uracil}$. Again, to confirm whether this in vitro DNA repair substrate contained uracil, the purified substrate was treated with UDG [20] and then APE1 [21, 22]. UDG catalyzes the release of free uracil from uracil-containing DNA, producing the AP site. Thus, upon incubation with UDG, no change in migratory behavior of pBS2/uracil was observed on agarose gel (Fig. 4c, lane 3). When UDG and APE1 were incubated with the uracil containing DNA substrates, most of the supercoiled DNA substrates transformed into open circular plasmids (Fig. 4c, lane 4), suggesting that this method is able to produce uracil lesion within the plasmid DNA.

We used this method by recruiting restriction endonuclease and $\mathrm{T} 5$ exonuclease to induce site-specific DNA lesion in the plasmid. To simplify this method further, we attempted to synthesize the DNA substrate in one $1.5 \mathrm{ml}$ microcentrifugation tube. Figure $5 \mathrm{a}$, when compared with Fig. $2 \mathrm{~b}$, shows the experimental procedure for purification of $\mathrm{pBS} 2 / \mathrm{A}: \mathrm{C}$ omitting a DNA purification step. When this procedure was executed, population with incorporation of a mismatched oligonucleotide seemed to be better with respect to the
A

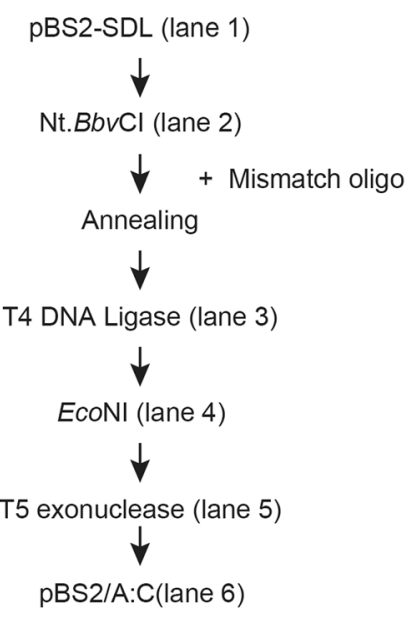

B

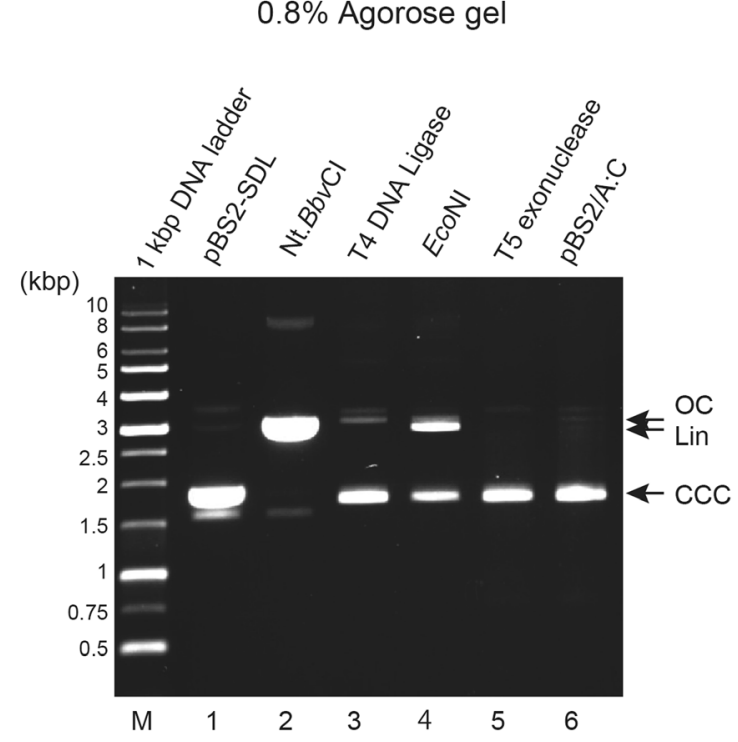

$0.8 \%$ Agorose gel

Fig. 5 One-pot synthesis of DNA repair substrate. a Experimental procedure for purification of pBS2/A:C omitting a column purification step. $\mathbf{b}$ Aliquots from various steps of the purification were subjected to $0.8 \%$ agarose gel electrophoresis, and the DNA substrates were visualized by staining with EtBr. Lane 1, pBS2-SDL; lane 2, Nt.BbvCl-treatment; lane 3, T4 DNA ligase-treatment; lane 4, EcoNI-treatment; lane 5, T5 exonuclease-treatment: lane 6, purified pBS2A:C by PCR purification kit. Open circular DNA (OC), liner DNA (Lin), and covalently closed circular DNA (CCC) are indicated by arrows. And the irreversibly denatured form was observed as the minor band shorter than the CCC band. 
procedure involving the additional DNA purification step (compare Fig. 2c, lane 5 and Fig. 5b, lane 4). Moreover, in the method containing the DNA purification step, $81.1 \%$ of products were digested by EcoNI, indicating $81.1 \%$ contamination, while in case of one-pot synthesis, only $53.6 \%$ of products were digested by EcoNI. Some reagents in the DNA purification step might interfere with the following reactions for the DNA synthesis. Thus, one-pot synthesis worked more efficiently under our experimental conditions. Therefore, we have successfully established the one-pot synthesis protocol for in vitro DNA repair substrate containing site-specific DNA lesion.

\section{Conclusions}

To analyze DNA repair mechanisms in vitro, DNA substrates having DNA lesions at particular sites are necessary. There are several procedures to produce the DNA lesion bearing substrate. In some cases, however, it is not easy to prepare the DNA substrate and proves to be expensive. Here we establish the procedure for preparing DNA substrate containing site-specific DNA lesion. This modified method using restriction enzyme and T5 exonuclease allows the preparation of the DNA substrate on which the DNA repair enzymes function. Moreover, one-pot synthesis method makes it more simple and convenient to prepare the DNA substrate. We believe that this method is useful to investigate DNA repair mechanisms in vitro.

\begin{abstract}
Abbreviations
6-4 pp.: pyrimidine (6-4) pyrimidone photoproduct; 8-oxoG: 8oxoguanine; AP: Apurinic/apyrimidinic site; APE1: Apurinic/apyrimidinic endonuclease; BER: Base excision repair; CPD: Cis-syn cyclobutane pyrimidine dimer; dsDNA: Double strand DNA; EtBr: Ethidium bromide; Fpg: Formamidopyrimidine [fapy]-DNA glycosylase; hOGG1: human 8oxoguanine DNA glycosylase; MMR: Mismatch repair; NER: Nucleotide excision repair; PCNA: Proliferating cell nuclear antigen; ssDNA: single strand DNA; UDG: Uracil-DNA Glycosylase
\end{abstract}

\section{Acknowledgements}

We would like to thank Editage (http://www.editage.jp) for English language editing.

\section{Funding}

This work was supported by a Grant-in-Aid for Scientific Research (B) 25281018 from the Ministry of Education, Culture, Sports, Science and Technology (MEXT) of Japan.

\section{Availability of data and materials}

Not applicable

\section{Authors' contributions}

YS and MH performed experimental work. SI designed the research. IK designed the research and wrote the manuscript. All authors have read and approved the final manuscript.

\section{Ethics approval and consent to participate}

Not applicable.

\section{Consent for publication}

Not applicable

\section{Competing interests}

The authors declare that they have no competing interests.

\section{Publisher's Note}

Springer Nature remains neutral with regard to jurisdictional claims in published maps and institutional affiliations.

Received: 5 September 2018 Accepted: 12 October 2018

Published online: 12 November 2018

\section{References}

1. Lindahl T, Wood RD. Quality control by DNA repair. Science. 1999;286: 1897-905.

2. Friedberg EC, Walker GC, Siede W, Wood RD, Schultz RA, Ellenberger T. DNA repair and mutagenesis. Washington, DC: American Society for Microbiology Press; 2005

3. Suzuki T, Kamiya H. Mutations induced by 8-hydroxyguanine (8-oxo-7,8dihydroguanine), a representative oxidized base, in mammalian cells. Genes Environ. 2017;39:2. https://doi.org/10.1186/s41021-016-0051-y.

4. Kubota Y, Nash RA, Klungland A, Schär P, Barnes DE, Lindahl T. Reconstitution of DNA base excision-repair with purified human proteins: interaction between DNA polymerase beta and the XRCC1 protein. EMBO J Eur Mol Biol Organ. 1996;15:6662-70.

5. Krokan HE, Bjoras M. Base excision repair. Cold Spring Harb Perspect Biol 2013;5: a012583-a012583. https://doi.org/10.1101/cshperspect.a012583.

6. Huang JC, Svoboda DL, Reardon JT, Sancar A. Human nucleotide excision nuclease removes thymine dimers from DNA by incising the 22nd phosphodiester bond 5" and the 6th phosphodiester bond 3" to the photodimer. Proc Natl Acad Sci. 1992;89:3664-8.

7. Moggs JG, Yarema KJ, Essigmann JM, Wood RD. Analysis of incision sites produced by human cell extracts and purified proteins during nucleotide excision repair of a 1,3-intrastrand d(GpTpG)-cisplatin adduct. J Biol Chem. 1996;271:7177-86.

8. Huang JC, Hsu DS, Kazantsev A, Sancar A. Substrate spectrum of human excinuclease: repair of abasic sites, methylated bases, mismatches, and bulky adducts. Proc Natl Acad Sci. 1994;91:12213-7. https://doi.org/10.1073/pnas.91.25.12213.

9. Matsumoto Y, Bogenhagen DF. Repair of a synthetic abasic site involves concerted reactions of DNA synthesis followed by excision and ligation. Mol Cell Biol. 1991;11:4441-7.

10. Matsumoto Y, Kim K, Bogenhagen DF. Proliferating cell nuclear antigendependent abasic site repair in Xenopus laevis oocytes: an alternative pathway of base excision DNA repair. Mol Cell Biol. 1994;14:6187-97.

11. Varlet I, Radman M, Brooks P. DNA mismatch repair in Xenopus egg extracts: repair efficiency and DNA repair synthesis for all single base-pair mismatches. Proc Natl Acad Sci. 1990:87:7883-7.

12. Wang H, Hays JB. Preparation of DNA substrates for in vitro mismatch repair. Mol Biotechnol. 2000;15:97-104. https://doi.org/10.1385/MB:15:2:97.

13. Wang $\mathrm{H}$, Hays JB. Mismatch repair in human nuclear extracts. J Biol Chem. 2002;277:26136-42. https://doi.org/10.1074/jbc.M200357200.

14. Du W, Kinsella TJ. A rapid, simple DNA mismatch repair substrate construction method. Front Oncol. 2011;1:8. https://doi.org/10.3389/fonc.2011.00008.

15. Sayers JR, Eckstein F. Properties of overexpressed phage T5 D15 exonuclease. Similarities with Escherichia coli DNA polymerase I 5"-3" exonuclease. J Biol Chem. 1990;265:18311-7.

16. Shivji MKK, Moggs JG, Kuraoka I, Wood RD. Dual-incision assays for nucleotide excision repair using DNA with a lesion at a specific site. In: DNA repair protocols. New Jersey: Humana Press; 1999. p. 373-92. https://doi.org/10.1385/1-59259-675-4:373.

17. Boiteux S, O'Connor TR, Laval J. Formamidopyrimidine-DNA glycosylase of Escherichia coli: cloning and sequencing of the fpg structural gene and overproduction of the protein. EMBO J. 1987;6:3177-83.

18. Tchou J, Bodepudi V, Shibutani S, Antoshechkin I, Miller J, Grollman AP, et al. Substrate specificity of Fpg protein. Recognition and cleavage of oxidatively damaged DNA. J Biol Chem. 1994;269:15318-24.

19. Bjoras M, Luna L, Johnsen B, Hoff E, Haug T, Rognes T, et al. Opposite basedependent reactions of a human base excision repair enzyme on DNA containing 7,8-dihydro-8-oxoguanine and abasic sites. EMBO J. 1997;16: 6314-22. https://doi.org/10.1093/emboj/16.20.6314. 
20. Lindahl T, Ljungquist S, Siegert W, Nyberg B, Sperens B. DNA N-glycosidases: properties of uracil-DNA glycosidase from Escherichia coli. J Biol Chem. 1977;252:3286-94.

21. Demple B, Herman T, Chen DS. Cloning and expression of APE, the CDNA encoding the major human apurinic endonuclease: definition of a family of DNA repair enzymes. Proc Natl Acad Sci. 1991;88:11450-4.

22. Robson CN, Hickson ID. Isolation of CDNA clones encoding a human apurinic/apyrimidinic endonuclease that corrects DNA repair and mutagenesis defects in E. coli xth (exonuclease III) mutants. Nucleic Acids Res. 1991;19:5519-23.

Ready to submit your research? Choose BMC and benefit from:

- fast, convenient online submission

- thorough peer review by experienced researchers in your field

- rapid publication on acceptance

- support for research data, including large and complex data types

- gold Open Access which fosters wider collaboration and increased citations

- maximum visibility for your research: over $100 \mathrm{M}$ website views per year

At BMC, research is always in progress.

Learn more biomedcentral.com/submissions 